\title{
THE IMPLEMENTATION OF CONTEXTUAL TEACHING AND LEARNING IN LEARNING INDONESIAN AT SD 002 SUNGAI SALAK
}

\author{
Yenni Susanti \\ SD 002 Sungai Salak, Inhil, Indonesia \\ yennisusanti6@gmail.com
}

\begin{abstract}
The purpose of this study was to improve learning outcomes in Indonesian through contextual teaching and learning model. This study was classroom action research conducted at SD 002 Sungai Salak involving 17 students. The results of this study showed that the teachers' activity in meeting I of Cycle I was scored 53.57\% with Good category. In meeting II of Cycle I, it increased to 71.43. Then, the score of teachers' activit from meeting III to meeting IV increased by 3.57\%. In addition, the score of students' activity in meeting I of Cycle I was $50.00 \%$ with sufficient category. Then, in meeting II of Cycle I, it increased to 60.71\%. In meeting II of Cycle II, the score of students' activity was $75.00 \%$ with Good category, and in meeting IV of Cycle II, the score of students' activity was $78.57 \%$ with Very Good category. Then, the students' activities increased by $3.57 \%$ in meeting III and meeting IV. The students' learning outcomes on Bahasa Indonesia increased after learning through Contextual Teaching and Learning model. The results of the test showed that the total score of of daily test was 1240 with the class average of 72.94 in which 11 students reached the target score while 6 students did not reach the target score. Meanwhile, the total score in Cycle II was 1420 with an average of 83.53 in which 15 students reached the target score and 2 students did not reach the tearget score.
\end{abstract}

Keywords: contextual teaching and learning

\section{PENERAPAN CONTEXTUAL TEACHING AND LEARNING DALAM PEMBELAJARAN BAHASA INDONESIA DI SD 002 SUNGAI SALAK}

\begin{abstract}
ABSTRAK
Tujuan penelitian ini adalah untuk meningkatkan hasil belajar bahasa Indonesia dengan menggunakan model contextual teaching and learning. Metode penelitian ini dengan menggunakan penelitian tindakan kelas di SD 002 Sungai Salak dengan jumlah siswa 17 orang. Hasil penelitian ini pada pertemuan pertama siklus I, skor aktivitas guru 53.57\% dengan kategori Baik. Pada pertemuan kedua siklus I skor aktivitas guru 71.43. Pertemuan ketiga ke pertemuan keempat aktivitas guru meningkat sebanyak 3.57\%. Pada pertemuan pertama siklus I, skor aktivitas siswa 50.00\% dengan kategori Cukup. Pada pertemuan kedua siklus I skor aktivitas siswa 60.71\%. Pada pertemuan ketiga siklus II skor aktivitas siswa 75.00\% dengan kategori Baik. Pada pertemuan keempat siklus II skor aktivitas siswa $78.57 \%$ dengan kategori Amat Baik. Pertemuan ketiga ke pertemuan keempat aktivitas siswa meningkat sebanyak 3.57\%. Hasil belajar bahasa Indonesia Setelah dilakukan pembelajaran model Contextual Teaching and Learning dengan memberikan ulangan harian I dengan jumlah skor 1240 dengan rata-rata kelas 72.94 dengan keterangan ketuntasan siswa yang tuntas 11 orang yang tidak tuntas 6 orang, sedangkan pada siklus II dengan jumlah skor 1420 dengan rata-rata 83.53 dengan keterangan ketuntasan siswa yang tuntas sebanyak 15 orang yang tidak tuntas 2 orang siswa.
\end{abstract}

Kata Kunci: contextual teaching and learning

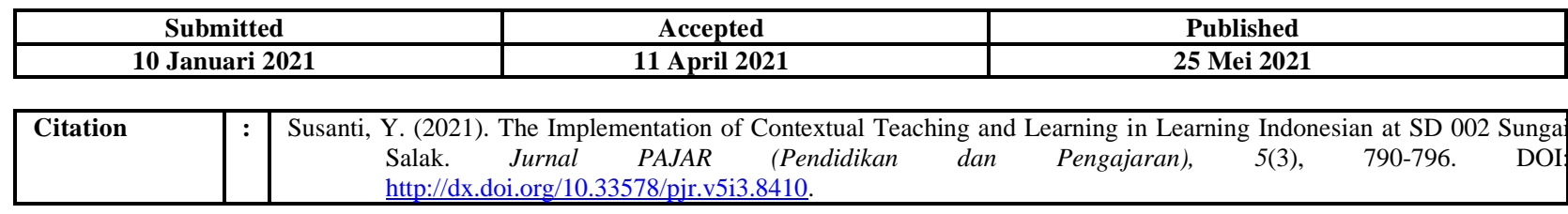

\section{PENDAHULUAN}

Pembelajaran di kelas merupakan tanggung jawab dari guru sebagai pelaksana dan pengatur dalam pembelajaran yang akan dirangsang oleh siswa yang memiliki sumber dan guru akan memberikan fasilitas pemahaman kepada siswa (Hamdu \& Yulianto, 2018). Peran guru untuk meningkatkan intelektual siswa dalam proses berpikir serta merangsang pembelajaran terhadap kemampuan siswa menguasai bahasa Indonesia (Kurniaman dkk, 2019). Pembelajaran 
Kontekstual (Contextual Teaching and Learning) atau CTL merupakan konsep pembelajaran yang menekankan pada keterkaitan antara materi pembelajaran dengan dunia kehidupan siswa secara nyata, sehingga siswa mampu menghubungkan dan menerapkan kompetensi dalam kehidupan sehari-hari (Mulyasa, 2007). Menurut Sanjaya (2010) mengemukakan bahwa CTL adalah suatu konsep pembelajaran yang menekankan kepada proses keterlibatan siswa secara penuh untuk dapat menemukan materi yang dipelajari dan menghubungkannya dengan situasi kehidupan nyata. Menurut Yunelmi (2018) model Contextual Teaching and Learning (CTL) merupakan model pembelajaran yang bertujuan membantu siswa melihat makna dalam bahan pelajaran yang mereka pelajari dengan cara menghubungkannya dengan konteks kehidupan mereka sehari-hari yaitu, dengan konteks lingkungan pribadi, sosial, dan budayanya.

Menurut Nurhadi (2004) merumuskan bahwa CTL merupakan suatu proses pendidikan yang bertujuan membantu siswa melihat makna/arti dalam bahan pelajaran yang mereka pelajari dengan cara menghubungkannya dengan konteks kehidupan sehari-hari, yaitu dengan konteks lingkungan pribadi, sosial, dan budayanya. Adapun menurut Muslich (2007), CTL adalah konsep belajar yang membantu guru mengaitkan antara materi pembelajaran dengan situasi dunia nyata siswa, dan mendorong siswa membuat hubungan antara pengetahuan yang dimilikinya dengan penerapannya dalam kehidupan sehari-hari. Sering kali pembelajaran susah sekali untuk dipahami oleh siswa karena kekurangan guru dalam menghubungkan pembelajaran dengan kehidupan anak sehari-hari (Hutauruk, Gaol, Mahulae, \& Tanjung, 2020) dengan model kontektual ini siswa akan diberikan materi dengan dihubungkan dengan apa yang siswa alami sehingga mampu memberikan pemahaman yang lama.

\section{KAJIAN TEORETIS}

Belajar bahasa tidak akan melakukan aktivitas menghafal sebagai kegiatan pokok, tetapi siswa lebih banyak melakukan menemukan yang diperoleh dari aktivitas pengalaman siswanya
(Santoso dkk, 2018). Langkah-Langkah pelaksanaan proses pembelajaran Kontekstual menurut Nurhadi (2004), yaitu:

\section{Konstruktivisme (Constructivism)}

Komponen ini merupakan landasan berfikir (filosofi) pembelajaran CTL, yaitu bahwa pengetahuan dibangun oleh manusia sedikit demi sedikit, yang hasilnya diperluas melalui konteks yang terbatas (sempit) dan tidak sekonyongkonyong (Nurhadi, 2004). Pembelajaran konstruktivisme menekankan terbangunnya pemahaman sendiri secara aktif, kreatif dan produktif berdasarkan pengetahuan terdahulu dan dari pengalaman belajar yang bermakna. Dalam materi pembelajaran bahasa Indonesia Siswa di beri kesempatan untuk membaca ilustrasi tentang benda bergerak agar memperoleh gambaran konkrit tentang gaya dan gerak di sekitar mereka. kemudian siswa mempraktekkan dengan kegiatan membuka dan menutup pintu . dengan demikian akan terbangun pemahaman secara aktif.

\section{Inkuiri (Menemukan)}

Menurut Nurhadi (2004), inkuiri adalah suatu ide yang kompleks, yang berati banyak hal bagi banyak orang. Inkuiri (Sanjaya: 2010), artinya proses pembelajaran didasarkan pada pencarian dan penemuan melalui proses berpikir secara sistematis. Komponen ini merupakan kegiatan inti CTL. Diawali dari pengamatan terhadap fenomena, dilanjutkan dengan kegiatankegiatan bermakna untuk menghasilkan temuan yang diperoleh sendiri oleh siswa. Dengan demikian pengetahuan dan keterampilan yang diperoleh tidak dari hasil mengingat seperangkat fakta, tetapi hasil menemukan sendiri dari fakta yang dihadapinya.

Langkah-langkah kegiatan inquiry, Nurhadi (2004) merumuskan masalah; mengumpulkan data melalui observasi; menganalisis dan menyajikan hasil dalam tulisan, gambar, laporan, bagan, tabel, dan karya lain; dan menyajikan hasil karya pada pembaca, teman sekelas, audiens yang lain. Kemudian dilanjutkan dengan menceritakan pengalaman siswa mengenai gaya dan gerak dan menemukan gambaran tentang materi apa yang akan dipelajari. Selanjutnya siswa diberikan teks tentang gaya dan menemukan kosa kata baku didalamnya. 
3 Bertanya (Questioning)

Menurut Nurhadi (2004), pengetahuan yang dimiliki seseorang selalu bermula dari bertanya. Guru menggunakan pertanyaanpertanyaan untuk menuntun siswa berpikir dan untuk membuat penilaian secara kontinyu terhadap pemahaman siswa. Bertanya dalam pembelajaran dipandang sebagai kegiatan guru untuk mendorong, membimbing, dan menilai kemampuan berpikir siswa. Siswa belajar mengajukan pertanyaan tentang gejala-gejala yang ada, belajar bagaimana merumuskan pertanyaanpertanyaan yang dapat diuji, belajar saling bertanya tentang bukti, interprestasi, dan penjelasan-penjelasan yang ada. Pertanyaan dapat digunakan untuk berbagai macam tujuan, berbagai macam bentuk, dan berbagai macam jawaban yang ditimbulkannya. Setelah siswa mempraktekkan gerakan membuka dan menutup pintu guru memberikan pertanyaan seputar materi " apakah pintu tersebut bergerak ?" Gejala apa yang terjadi. 4 Masyarakat Belajar (Learning Community)

Komponen ini menyarankan bahwa prestasi belajar sebaiknya diperoleh dari kerja sama dengan orang lain. Prestasi belajar bisa diperoleh dengan sharing antar teman, kelompok, dan antara yang tahu kepada yang tidak tahu, baik di dalam maupun di luar kelas. Komponen ini terjadi apabila ada proses komunkasi dua arah. Karena pembelajaran yang dikemas dalam diskusi kelompok dengan anggota heterogen dan jumlah yang bervariasi sangat mendukung komponen ini. Anggota kelompok yang terlibat dalam komunikasi pembelajaran dapat saling belajar. Kegiatan dilanjutkan dengan menjawab beberapa pertanyaan yang ada di buku siswa. Siswa bersama teman sebangkunya mendiskusikan jawaban dari pertanyaan tersebut.

5) Pemodelan (Modeling)

Modeling adalah proses pembelajaran dengan memperagakan sesuatu sebagai contoh yang dapat ditiru oleh setiap siswa (Sanjaya, 2010). Modeling merupakan asas yang cukup penting dalam pembelajaran CTL, sebab melalui modeling siswa dapat terhindar dari pembelajaran yang teoritis-abstrak yang dapat memungkinkan terjadinya verbalisme. Menurut Nurhadi (2004) pemodelan pada dasarnya membahasakan gagasan yang dipikirkan, mendemonstrasikan bagaimana guru menginginkan siswanya untuk belajar, dan melakukan apa yang guru inginkan agar siswanya melakukan.

Pemodelan dapat berbentuk demonstrasi, pemberian contoh tentang konsep atau aktivitas belajar. Contoh itu bukan untuk ditiru persis, tapi menjadi acuan pencapaian kompetensi siswa. Dalam kontekstual, guru bukan satu-satunya model, tapi model itu dapat dirancang dengan melibatkan siswa. Model juga dapat didatangkan dari luar. Guru dapat memberi contoh tentang cara bekerja sesuatu sebelum peserta didik melaksanakan tugas (Santoso, 2017) Pada tahap ini guru memperagakan bagaimana proses perpindahan suatu barang atau benda dengan mendorong meja belajar. Guru bersama siswa melakukan beberapa gerakan gerakan yang dapat menghasilkan gaya.

6) Refleksi (Reflection)

Refleksi Nurhadi (2004) adalah cara berpikir tentang apa yang baru dipelajari atau berpikir ke belakang tentang apa-apa yang sudah kita laukan di masa yang baru saja kita terima. Releksi merupakan respon terhadap kejadian, aktivitas, atau pengetahuan terhadap apa yang baru diterima. Guru membantu siswa membuat hubungan-hubungan antara pengetahuan yang dimiliki sebelumnya dengan pengetahuan yang baru. Dengan begitu, siswa merasa memperoleh sesuatu yang berguna bagi dirinya tentang apa baru dipelajarinya. Guru perlu melaksanakan refleksi pada akhir program pembelajaran. Guru menyisakan waktu sejenak agar siswa melakukan refleksi berupa:

a) pertanyaan langsung tentang apa-apayang diperolehnya hari itu,

b) catatan atau jurnal di buku siswa,

c) kesan dan saran siswa mengenai pembelajaran hari itu,

d) diskusi,

e) hasil karya, dan

f) catatan lain yang ditempuh guru untuk mengarahkan siswa kepada pemahaman mereka tentang materi yang dipelajari.

7) Penilaian Nyata (Authentic Assesment) 
Menurut Nurhadi (2004) pada hakikatnya, penilaian yang benar adalah menilai apa yang seharusnya dinilai. Penilaian nyata adalah proses yang dilakukan guru untuk mengumpulkan informasi tentang perkembangan belajar yang dilakukan siswa (Sanjaya: 2010: 122). Penilaian harus menekankan kedalam pengetahuan dan keahlian siswa, bukan keluasanya (kuantitas). Guru menilai bagaimana sikap siswa dalam proses pemeblajaran bagaimana sikap bertanggung jawab dan sikap mandiri serta bagaimana proses siswa dalam menjawab pertanyaan-pertanyaan.

\section{METODE PENELITIAN}

Metode penelitian yang dilakukan dengan menggunakan penelitian tindakan kelas yang merupakan penelitian praktis yang dimaksudkan untuk memperbaiki pembelajaran di kelas. Penelitian ini merupakan salah satu upaya guru atau praktisi dalam bentuk berbagai kegiatan yang dilakukan untuk memperbaiki dan atau meningkatkan mutu pembelajaran di kelas. PTK dapat diartikan sebagai proses pengkajian masalah pembelajaran di dalam kelas melalui refleksi diri dalam upaya untuk memecahkan masalah tersebut dengan cara melakukan berbagai tindakan yang terencana dalam situasi nyata serta menganalisis setiap pengaruh dari perlakuan tersebut (Sanjaya, 2016). Pelaksanaan penelitian tindakan kelas ini dilakukan di kelas IV dengan jumlah siswa lakilaki 9 orang, dan 8 orang perempuan dengan total jumlah siswa sebanyak 17 orang. Instrument dalam penelitian ini berupa perangkat pembelajaran, dan soal UH yang dilaksanakan diakhir siklus.

Data yang dikumpulkan pada penelitian ini meliputi : 1) Data observasi yang diperoleh pada penelitian ini adalah aktivitas guru dan aktivitas siswa selama proses pembelajaran dan hasil belajar siswa setelah proses pembelajaran. 2) Data tes hasil belajar bahasa Indonesia yaitu untuk mengetahui tingkat pemahaman dan hasil belajar siswa sesuai dengan KKM yang ditetapkan sekolah. Ulangan harian dilakukan secara 2 tahap. Tahap pertama pada siklus I dan kedua pada siklus II setelah dilakukan pembelajaran. Ulangan harian berupa objektif atau pilihan ganda.

\section{HASIL DAN PEMBAHASAN}

Hasil penelitian yang akan dibahas merupakan data aktivitas guru dan aktivitas siswa selama proses pelaksanaan pembelajaran dengan menerapkan model Contextual Teaching and Learning. Selain aktivitas guru dan aktivitas siswa, hasil penelitian yang akan dibahas dalam penelitian ini adalah ketuntasan hasil belajar bahasa Indonesia siswa kelas IV SD 002 Sungai Salak pada siklus pertama dan kedua. Terlihat pada tabel 1 di bawah ini.

Tabel 1. Aktivitas Guru Kelas IV SD 002 Sungai Salak

\begin{tabular}{ccccc}
\hline \multirow{2}{*}{ Siklus } & Pertemuan & Jumlah Skor & $\%$ & Kategori \\
\hline \multirow{2}{*}{ I } & I & 15 & 53.57 & Baik \\
& II & 20 & 71.43 & Baik \\
II & III & 25 & 89.29 & Amat Baik \\
& IV & 26 & 92.86 & Amat Baik \\
\hline
\end{tabular}

Aktivitas guru pada setiap pertemuan dalam penerapan model Contextual Teaching and Learning. Pada pertemuan pertama siklus I, skor aktivitas guru $53.57 \%$ dengan kategori Baik. Pada pertemuan kedua siklus I skor aktivitas guru 71.43 mengalami peningkatan sebanyak $17.86 \%$. Pada pertemuan ini guru sudah bisa mengontrol siswa dan mulai bisa menguasai kelas. Pada pertemuan ketiga siklus II skor aktivitas guru $89.29 \%$ dengan kategori Amat Baik. Pada pertemuan kedua siklus I ke pertemuan ketiga siklus II mengalami peningkatan sebanyak $17.86 \%$. Pada pertemuan keempat siklus II skor aktivitas guru meningkat menjadi $92.86 \%$ dengan kategori Amat Baik. Pertemuan ketiga ke pertemuan keempat aktivitas guru meningkat sebanyak $3.57 \%$.

Dari penjelasan di atas dapat disimpulkan bahwa terjadi peningkatan aktivitas guru pada 
setiap pertemuan karena guru sudah mulai terbiasa menerapkan model Contextual Teaching and Learning, sehingga setiap tindakan atau aktivitas yang dilakukan sesuai dengan langkah-langkah model pembelajaran yang akan diterapkan, hal ini terlihat dari aktifnya guru membimbing siswa baik pada saat siswa mengerjakan LKS maupun pada saat memberikan masukan dan saran pada akhir pembelajaran. Untuk aktivitas siswa akan terlihat pada tabel 2 di bawah ini.

Tabel 2. Aktivitas Siswa Kelas IV SD 002 Sungai Salak

\begin{tabular}{ccccc}
\hline \multirow{2}{*}{ Siklus } & Pertemuan & Jumlah Skor & $\%$ & Kategori \\
& & & & \\
\hline \multirow{2}{*}{ I } & I & 14 & 50.00 & Cukup \\
& II & 17 & 60.71 & Baik \\
II & III & 21 & 75.00 & Baik \\
& IV & 22 & 78.57 & Amat Baik \\
\hline
\end{tabular}

Aktivitas siswa pada setiap pertemuan dalam penerapan model Contextual Teaching and Learning mengalami peningkatan. Pada pertemuan pertama siklus I, skor aktivitas siswa $50.00 \%$ dengan kategori Cukup. Pada pertemuan kedua siklus I skor aktivitas siswa $60.71 \%$ mengalami peningkatan sebanyak $10.71 \%$. Pada pertemuan ketiga siklus II skor aktivitas siswa $75.00 \%$ dengan kategori Baik. Pada pertemuan kedua siklus I ke pertemuan ketiga siklus II mengalami peningkatan sebanyak $14.29 \%$. Pada pertemuan keempat siklus II skor aktivitas siswa $78.57 \%$ dengan kategori Amat Baik. Pertemuan ketiga ke pertemuan keempat aktivitas siswa meningkat sebanyak $3.57 \%$. Peningkatan aktivitas siswa pada setiap pertemuan terjadi karena siswa telah memahami langkah-langkah model Contextual Teaching and Learning, dimana siswa harus aktif terlibat dalam proses pembelajaran, siswa bisa belajar dari teman melalui kerja kelompok, berdiskusi dan saling mengoreksi dan keterampilan dikembangkan atas dasar pemahaman serta siswa menemukan dan menerapkan idenya sendiri dengan bimbingan guru. Hasil belajar bahasa Indonesia akan terlihat pada tabel 3 yang didapat dengan melakukan ulangan harian.

Tabel 3. Hasil Belajar Bahasa Indonesia Siswa Kelas IV SD 002 Sungai Salak

\begin{tabular}{cccccccc}
\hline No & Kode Siswa & $\begin{array}{c}\text { Skor } \\
\text { Dasar }\end{array}$ & Ket & UH I & Ket & UH II & Ket \\
\hline 1 & Siswa - 01 & 60 & TT & 70 & $\mathrm{~T}$ & 85 & $\mathrm{~T}$ \\
2 & Siswa - 02 & 55 & $\mathrm{TT}$ & 70 & $\mathrm{~T}$ & 80 & $\mathrm{~T}$ \\
3 & Siswa - 03 & 50 & $\mathrm{TT}$ & 70 & $\mathrm{~T}$ & 80 & $\mathrm{~T}$ \\
4 & Siswa - 04 & 75 & $\mathrm{~T}$ & 100 & $\mathrm{~T}$ & 100 & $\mathrm{~T}$ \\
5 & Siswa - 05 & 45 & $\mathrm{TT}$ & 50 & $\mathrm{TT}$ & 75 & $\mathrm{~T}$ \\
6 & Siswa - 06 & 40 & $\mathrm{TT}$ & 45 & $\mathrm{TT}$ & 60 & $\mathrm{TT}$ \\
7 & Siswa - 07 & 75 & $\mathrm{~T}$ & 85 & $\mathrm{~T}$ & 95 & $\mathrm{~T}$ \\
8 & Siswa - 08 & 95 & $\mathrm{~T}$ & 100 & $\mathrm{~T}$ & 100 & $\mathrm{~T}$ \\
9 & Siswa - 09 & 70 & $\mathrm{~T}$ & 90 & $\mathrm{~T}$ & 95 & $\mathrm{~T}$ \\
10 & Siswa - 10 & 70 & $\mathrm{~T}$ & 95 & $\mathrm{~T}$ & 100 & $\mathrm{~T}$ \\
11 & Siswa - 11 & 35 & $\mathrm{TT}$ & 70 & $\mathrm{~T}$ & 80 & $\mathrm{~T}$ \\
12 & Siswa - 12 & 55 & $\mathrm{TT}$ & 60 & $\mathrm{TT}$ & 75 & $\mathrm{~T}$ \\
13 & Siswa - 13 & 40 & $\mathrm{TT}$ & 55 & $\mathrm{TT}$ & 70 & $\mathrm{~T}$ \\
14 & Siswa - 14 & 70 & $\mathrm{~T}$ & 95 & $\mathrm{~T}$ & 100 & $\mathrm{~T}$ \\
\hline
\end{tabular}


Jurnal PAJAR (Pendidikan dan Pengajaran)

Volume 5 Nomor 3 April 2021 | ISSN Cetak : 2580 - 8435 | ISSN Online : 2614 - 1337

DOI : http://dx.doi.org/10.33578/pjr.v5i3.8410

\begin{tabular}{cccccccc}
\hline 15 & Siswa -15 & 35 & TT & 45 & TT & 70 & T \\
16 & Siswa -16 & 35 & TT & 40 & TT & 55 & TT \\
17 & Siswa -17 & 85 & $\mathrm{~T}$ & 100 & $\mathrm{~T}$ & 100 & $\mathrm{~T}$ \\
& Jumlah & 990 & $\mathrm{~T}=7$ & 1240 & $\mathrm{~T}=11$ & 1420 & $\mathrm{~T}=15$ \\
& Rata-rata & 58.24 & $\mathrm{TT}=10$ & 72.94 & $\mathrm{TT}=6$ & 83.53 & $\mathrm{TT}=2$ \\
\hline
\end{tabular}

Hasil belajar bahasa Indonesia pada skor awal yang dilakukan sebelum melaksanakan pembelajaran dengan menggunakan model Contextual Teaching and Learning dengan jumlah skor 990 dengan rata-rata 58.24, dengan keterangan ketuntasan siswa yang tuntas 7 orang dan yang tidak tuntas 10 orang. Setelah dilakukan pembelajaran model Contextual Teaching and Learning dengan memberikan ulangan harian I dengan jumlah skor 1240 dengan rata-rata kelas 72.94 dengan keterangan ketuntasan siswa yang tuntas 11 orang yang tidak tuntas 6 orang, sedangkan pada siklus II dengan jumlah skor 1420 dengan rata-rata 83.53 dengan keterangan ketuntasan siswa yang tuntas sebanyak 15 orang yang tidak tuntas 2 orang siswa. Pembelajaran yang memberikan kebermaknaan kepada siswa akan lebih memberikan pembelajaran yang lebih baik (Kurniaman \& Huda, 2018) terlihat dalam penelitian ini. Menjadi guru harus mampu mengeluarkan potensi-potensi siswa dengan konsep kontektual sehingga mampu memaksimalkan kondisi yang ada (Jackson \& Cho, 2018).

\section{SIMPULAN DAN REKOMENDASI}

Kesimpulan dalam penelitian ini terlihat pada aktivitas guru yang melaksanakan pembelajaran dengan menggunakan model Contextual Teaching and Learning ada mengalami peningkatan yang dilakukan guru dalam setiap pertemuan sehingga kekurangan dan kelemahan dalam pembelajaran bisa dilakukan perbaikan setelah dilakukan refleksi pembelajaran sehingga kelemahan dalam aktivitas siswa juga bisa diperbaiki yang menjadi kelemahan dalam pembelajaran. Dilihat dari hasil belajar bahasa Indonesia siswa pun mengalami peningkatan dilihat dari hasil rata-rata persiklus mengalami peningkatan. Untuk saran dalam penelitian ini diharapkan persiapan guru lebih matang lagi sehingga pelaksanaan pembelajaran lebih baik, serta memberikan kondisi kelas yang lebih baik dengan membuat permainan-permainan kecil yang bisa dilaksanakan di kelas.

\section{DAFTAR PUSTAKA}

Hamdu, G., \& Yulianto, A. (2018). The Ability of Prospective Elementary School Teachers to Develop Student Worksheets on ContextBased Science Learning. Mimbar Sekolah Dasar, 5(3), 155-161. doi:http://dx.doi.org/10.17509/mimbarsd.v5i3.14503.

Hutauruk, I., Gaol, R.L., Mahulae, S., \& Tanjung, D.S. (2020). The Effect of Contextual Teaching and Learning (CTL) Model on Students' Learning Outcomes in the Theme of "Daerah Tempat Tinggalku". Primary: Jurnal Pendidikan Guru Sekolah Dasar, 9(6), 900909.

DOI: http://dx.doi.org/10.33578/jpfkip.v9i6.8035.

Jackson, D. O., \& Cho, M. (2018). Language teacher noticing: A socio-cognitive window on classroom realities. Language Teaching Research, 22(1), 29-46.

Kurniaman, O., Noviana, E., Hermita, N., Maharani, D. S., Marwan, A., \& Afendi, N. (2019). Critical Thinking Analysis of Reading With Graphic Organizer Media in Elementary School. Proceeding of the SS9 \& $3 r d$ URICES, 2019, Pekanbaru, Indonesia.

Kurniaman, O., \& Huda, M. N. (2018). Penerapan Strategi Bercerita Untuk Meningkatkan Keterampilan Menyimak Siswa Kelas III SD Muhamadiyah 6 Pekanbaru. Primary: Jurnal Pendidikan Guru Sekolah Dasar, 7(2), 249255. 
Mulyasa. (2007). Standar Kompetensi dan Sertifikasi Guru. Bandung : PT Remaja Rosdakarya.

Muslisch, M. (2007). Melakukan PTK Itu Mudah. Jakarata: Bumi Aksara.

Nurhadi. (2004). Pembelajaran Kontekstual dan penerapannya dalam $K B K$. Malang: UM Press.

Sanjaya, W. (2010). Strategi Pembelajaran Berorientasi Standar Pendidikan. Jakarta: Kencana.

Santoso, dkk. (2018). Materi dan Pembelajaran Bahasa Indonesia SD. Jakarta: Universitas Terbuka.

Santoso, E. (2017). Penggunaan Model Pembelajaran Kontekstual Untuk Meningkatkan Pemahaman Matematika Siswa Sekolah Dasar. Jurnal Cakrawala Pendasar, 3(1), 22-30.

Sanjaya, W. (2016). Penelitian Tindakan Kelas. Bandung: Prenada Media.

Yunelmi. (2018). Penerapan Model Pembelajaran Ctl Untuk Meningkatkan Hasil Belajar Ppkn Siswa Kelas VIII Smp Negeri 2 Teluk Kuantan, Jurnal PAJAR (Pendidikan dan Pengajaran), 2(5), 777. 